\title{
EFEITO DA TEMPERATURA NA MASSA ESPECÍFICA DE ÉSTERES METÍLICOS DE ÁCIDOS GRAXOS
}

César Augusto Canciam

Mestre em Engenharia Química, professor lotado no Departamento Acadêmico de Engenharia Química da Universidade Tecnológica Federal do Paraná - Câmpus Ponta Grossa, canciam@utfpr.edu.br

Recebido em: 28/02/2014 - Aprovado em: 30/06/2014 - Disponibilizado em: 30/07/2014

RESUMO: A massa específica é um importante parâmetro físico-químico usado na caracterização dos materiais, sendo dependente da temperatura e da pressão. O objetivo desse trabalho foi avaliar o efeito da temperatura sobre a massa específica dos ésteres miristato de metila, pentadecanoato de metila, palmitato de metila, palmitoleato de metila, estearato de metila, oleato de metila, linoleato de metila e ariquidato de metila, utilizando o modelo proposto por Verduzco (2013). Para cada éster, foi encontrada uma relação do tipo Arrhenius. Os valores encontrados para a energia de ativação variaram de 809,77 a $833,54 \mathrm{~J} \mathrm{~mol}^{-1}$, em um intervalo de temperatura de 293,15 a $383,15 \mathrm{~K}$ e pressão de 1 atm. Constatou-se que quanto maior o comprimento da cadeia carbônica do éster metílico, maior é a energia de ativação. No entanto, o valor dessa grandeza decresce, quanto maior é o número de insaturações presentes na molécula. $\mathrm{Na}$ literatura, não foram encontrados valores experimentais da energia de ativação para a massa específica, o que dificultou a análise.

PALAVRAS-CHAVE: Ésteres. Efeito. Temperatura. Massa Específica.

\section{EFFECT OF TEMPERATURE ON SPECIFIC WEIGHT OF FATTY ACID METHYL ESTERS}

\begin{abstract}
The specific weight is an important physic-chemical parameter used for characterization of materials, being dependent on temperature and pressure. The objective of this work was evaluate the effect of temperature on specific weight of esters methyl myristate, methyl pentadecanoate, methyl palmitate, methyl palmitoleate, methyl stearate, methyl oleate, methyl linoleate and methyl arachidate, using the model proposed by Verduzco (2013). For each ester, it was found an Arrhenius-type relationship. The values found for the activation energy ranged from 809.77 to 833.54 J.mol ${ }^{-1}$, in the temperature range of 293.150 to $383.15 \mathrm{~K}$ and pressure equal to 1 atm. It was found that the greater the length of the carbon chain of the ester, the higher the activation energy. However, the value of this magnitude decreases with the greater the number of unsaturations present in the molecule. In the literature, it was not found experimental values of activation energy for specific weight, difficulting the analysis.
\end{abstract}

KEYWORDS: Esters. Effect. Temperature. Specific weight.

\section{INTRODUÇÃOO}

O uso de recursos renováveis, como óleos vegetais e gorduras, tem atraído diversas áreas de estudo, devido ao grande potencial para substituição de derivados petroquímicos, além de serem biodegradáveis e de custo relativamente baixo (NICOLAU et al., 2007).
De acordo com a Resolução no 42 de 24 de novembro de 2004 da Agência Nacional do Petróleo (ANP), Biodiesel (B100) é definido como sendo o combustível composto de alquil-ésteres de ácidos graxos de cadeia longa, derivados de óleos vegetais ou de gorduras animais (ENCARNAÇÃO, 2007).

Segundo Nicolau e coautores (2007), a primeira etapa de transformação dos óleos 
vegetais e gorduras em biodiesel é a reação de transesterificação.

A reação de transesterificação corresponde a uma reação orgânica, na qual um éster é transformado em outro através da troca de grupos alcóxidos. Assim, na transesterificação de óleos vegetais e gorduras, um triglicerídeo reage com um álcool, na presença de um catalisador, produzindo uma mistura de ésteres monoalquílicos de ácidos graxos e glicerol (GARCIA, 2006).

Os ésteres graxos produzidos através da reação de transesterificação são insumos básicos para uma ampla variedade de derivados oleoquímicos com alto valor agregado. No caso dos ésteres monoalquílicos, esses podem ser utilizados na produção de polímeros, lubrificantes, produtos de higiene pessoal, papel e alimentos (GARCIA, 2006).

Dados da massa específica são importantes para inúmeras unidades de Engenharia Química. Por exemplo, nas indústrias oleoquímicas, dados da massa específica são usados no projeto de reatores, em unidades de destilação, tanques de estocagem e instalações de bombeamento (CAVALCANTE, 2010).

No caso dos alquil-ésteres de ácidos graxos quando usados como combustíveis, a massa específica afeta diretamente as características de desempenho do motor, pois os motores são projetados para funcionarem com combustíveis em uma determinada faixa de massa específica. Variações na massa específica levam a uma significativa variação na massa de combustível injetada, impossibilitando a obtenção de uma mistura ar-combustível adequada (GARCIA, 2006; CAVALCANTE, 2010).

De maneira geral, a massa específica de um combustível influencia a partida, a pressão de injeção e a pulverização do combustível, interferindo no desempenho do motor de combustão e na emissão de poluentes (GARCIA, 2006; CAVALCANTE, 2010).

Equações do tipo Arrhenius permitem modelar matematicamente um determinado parâmetro físico-químico, bem como verificar o efeito da temperatura sobre esse parâmetro. É o que acontece com a viscosidade absoluta $(\mu)$ e a massa específica $(\rho)$. A Equação 1 expressa a viscosidade absoluta em termos da temperatura absoluta (T) (GIAP, 2010). Enquanto que a Equação 2 expressa a massa específica em termos da temperatura absoluta (TSEN e KING, 2002).

$$
\begin{aligned}
& \mu=\mu_{\infty} \cdot \exp \left(\frac{E_{a}}{R \cdot T}\right) \\
& \rho=\rho_{\infty} \cdot \exp \left(\frac{E_{a}}{R \cdot T}\right)
\end{aligned}
$$

$\mathrm{Na}$ Equação 1, $\mu_{\infty}$ corresponde à viscosidade absoluta quando a temperatura tende ao infinito, $E_{a}$ corresponde à energia de ativação de fluxo viscoso e $R$, à constante universal dos gases ideais. 
De maneira análoga, na Equação 2, $\rho_{\infty}$ corresponde à massa específica quando a temperatura tende ao infinito, $E_{a}$ corresponde à energia de ativação para a massa específica e $R$, à constante universal dos gases ideais.

Com relação à energia de ativação de fluxo viscoso, essa grandeza indica a sensibilidade da viscosidade absoluta devido à variação da temperatura. Ou seja, quanto maior for a energia de ativação de fluxo viscoso, maior será a influência da temperatura. Dessa forma, valores elevados da energia de ativação de fluxo viscoso indicam uma mudança mais rápida na viscosidade absoluta com a temperatura (PEREIRA et al, 2003; SILVA, 2008).

Considerando a semelhança entre as Equações 1 e 2, com relação à energia de ativação para a massa específica, essa grandeza indica a sensibilidade da massa específica devido à variação da temperatura. Ou seja, valores elevados da energia de ativação para a massa específica indicam uma mudança mais rápida na massa específica com a temperatura.

O objetivo deste trabalho foi avaliar o efeito da temperatura sobre a massa específica dos ésteres metílicos de ácidos graxos miristato de metila, pentadecanoato de metila, palmitato de metila, palmitoleato de metila, estearato de metila, oleato de metila, linoleato de metila e ariquidato de metila. Para tanto, foi utilizada a modelagem empírica da massa específica desses ésteres proposta por
Verduzco (2013), em um intervalo de temperatura de 293,15 a 383,15 K e pressão de 1 atm.

\section{MATERIAIS E MÉTODOS}

A Equação 3, obtida do trabalho de Verduzco (2013), relaciona a massa específica de ésteres metílicos de ácidos graxos $(\rho)$ em função da massa molar do éster $(M)$ em g.mol ${ }^{-1}$, do número de insaturações (ligações duplas) presentes na cadeia carbônica do ácido graxo $(N)$ e da temperatura absoluta $(T)$ em K.

$$
\rho=1,069+\left(\frac{3,575}{M}\right)+(0,0113 \cdot N)-\left(7,41 \cdot 10^{-4} \cdot T\right)
$$

A unidade para a massa específica na Equação 3 corresponde a g.cm ${ }^{-3}$.

A Tabela 1 relaciona os valores considerados para a massa molar, o número de insaturações presentes na cadeia carbônica do ácido graxo e a fórmula molecular dos ésteres metílicos estudados.

Com base na Equação 3 e nos dados indicados na Tabela 1, foram estimados os valores da massa específica de cada éster em função da temperatura. Em termos de temperatura, as temperaturas consideradas foram de 293,15 K, 303,15 K, 313,15 K, $323,15 \mathrm{~K}, 333,15 \mathrm{~K}, 343,15 \mathrm{~K}, 353,15 \mathrm{~K}$, $363,15 \mathrm{~K}, 373,15 \mathrm{~K}$ e $383,15 \mathrm{~K}$. 
Tabela 1. Dados referentes aos ésteres metílicos de ácidos graxos estudados

\begin{tabular}{cccc}
\hline $\begin{array}{c}\text { Éster metílico de } \\
\text { ácido graxo }\end{array}$ & $\begin{array}{c}\text { Massa } \\
\text { molar } \\
\left(\mathrm{g} \cdot \mathrm{mol}^{-1}\right)\end{array}$ & $\begin{array}{c}\text { Número de } \\
\text { insaturações }\end{array}$ & $\begin{array}{c}\text { Fórmula } \\
\text { molecular }\end{array}$ \\
\hline $\begin{array}{c}\text { Miristato de } \\
\text { metila }\end{array}$ & 242,3975 & 0 & $\mathrm{C}_{15} \mathrm{H}_{30} \mathrm{O}_{2}$ \\
$\begin{array}{c}\text { Pentadecanoato de } \\
\text { metila }\end{array}$ & 256,4241 & 0 & $\mathrm{C}_{16} \mathrm{H}_{32} \mathrm{O}_{2}$ \\
$\begin{array}{c}\text { Palmitato de } \\
\text { metila }\end{array}$ & 270,4507 & 0 & $\mathrm{C}_{17} \mathrm{H}_{34} \mathrm{O}_{2}$ \\
$\begin{array}{c}\text { Palmitoleato de } \\
\text { metila }\end{array}$ & 268,4348 & 1 & $\mathrm{C}_{17} \mathrm{H}_{32} \mathrm{O}_{2}$ \\
$\begin{array}{c}\text { Linoleato de } \\
\text { metila }\end{array}$ & 294,4721 & 2 & $\mathrm{C}_{19} \mathrm{H}_{34} \mathrm{O}_{2}$ \\
$\begin{array}{c}\text { Oleato de metila } \\
\text { Estearato de } \\
\text { metila }\end{array}$ & 296,4879 & 1 & $\mathrm{C}_{19} \mathrm{H}_{36} \mathrm{O}_{2}$ \\
$\begin{array}{c}\text { Ariquidato de } \\
\text { metila }\end{array}$ & 326,5570 & 0 & $\mathrm{C}_{19} \mathrm{H}_{38} \mathrm{O}_{2}$ \\
\hline Fonte: Verduzco $(2013)$. & 0 & & \\
\hline $\mathrm{H}_{42} \mathrm{O}_{2}$
\end{tabular}

Adotou-se como sistema de unidades, o Sistema Internacional (SI). Assim, os valores encontrados para a massa específica de cada éster, através da Equação 3, foram convertidos para kg. $\mathrm{m}^{-3}$.

A Tabela 2 indica os valores encontrados para a massa específica dos ésteres miristato de metila e pentadecanoato de metila. Enquanto que a Tabela 3 indica os valores encontrados para a massa específica dos ésteres palmitato de metila e palmitoleato de metila.

\section{A Tabela 4 indica os valores} encontrados para a massa específica dos ésteres linoleato de metila e oleato de metila.

A Tabela 5 indica os valores encontrados para a massa específica dos ésteres estearato de metila e ariquidato de metila.
Tabela 2. Valores estimados para a massa específica dos ésteres miristato de metila e pentadecanoato de metila

\begin{tabular}{ccc}
\hline $\begin{array}{c}\text { Temperatura } \\
(\mathrm{K})\end{array}$ & $\begin{array}{c}\text { Miristato de } \\
\text { metila }\left(\mathrm{kg} \cdot \mathrm{m}^{-3}\right)\end{array}$ & $\begin{array}{c}\text { Pentadecanoato de } \\
\text { metila }\left(\mathrm{kg} . \mathrm{m}^{-3}\right)\end{array}$ \\
\hline 293,15 & 866,5 & 865,7 \\
303,15 & 859,1 & 858,3 \\
313,15 & 851,7 & 850,9 \\
323,15 & 844,3 & 843,5 \\
333,15 & 836,9 & 836,1 \\
343,15 & 829,5 & 828,7 \\
353,15 & 822,1 & 821,3 \\
363,15 & 814,7 & 813,9 \\
373,15 & 807,2 & 806,4 \\
383,15 & 799,8 & 799,0 \\
\hline
\end{tabular}

Fonte: Autor.

Tabela 3. Valores estimados para a massa específica dos ésteres palmitato de metila e palmitoleato de metila

\begin{tabular}{ccc}
\hline Temperatura $(\mathrm{K})$ & $\begin{array}{c}\text { Palmitato de } \\
\text { metila }\left(\mathrm{kg} . \mathrm{m}^{-3}\right)\end{array}$ & $\begin{array}{c}\text { Palmitoleato de } \\
\text { metila }\left(\mathrm{kg} \cdot \mathrm{m}^{-3}\right)\end{array}$ \\
\hline 293,15 & 865,0 & 876,4 \\
303,15 & 857,6 & 869,0 \\
313,15 & 850,5 & 861,6 \\
323,15 & 842,8 & 854,2 \\
333,15 & 835,4 & 846,8 \\
343,15 & 827,9 & 839,3 \\
353,15 & 820,5 & 831,9 \\
363,15 & 813,1 & 824,5 \\
373,15 & 805,7 & 817,1 \\
383,15 & 798,3 & 809,7 \\
\hline
\end{tabular}

Fonte: Autor.

Tabela 4. Valores estimados para a massa específica dos ésteres linoleato de metila e oleato de metila

\begin{tabular}{ccc}
\hline Temperatura $(\mathrm{K})$ & $\begin{array}{c}\text { Linoleato de } \\
\text { metila }\left(\mathrm{kg} \cdot \mathrm{m}^{-3}\right)\end{array}$ & $\begin{array}{c}\text { Oleato de } \\
\text { metila }\left(\mathrm{kg} \cdot \mathrm{m}^{-3}\right)\end{array}$ \\
\hline 293,15 & 886,5 & 875,1 \\
303,15 & 879,1 & 867,7 \\
313,15 & 871,7 & 860,3 \\
323,15 & 864,3 & 852,9 \\
333,15 & 856,9 & 845,5 \\
343,15 & 849,5 & 838,1 \\
353,15 & 842,1 & 830,7 \\
363,15 & 834,7 & 823,3 \\
373,15 & 827,2 & 815,9 \\
383,15 & 819,8 & 808,4 \\
\hline
\end{tabular}

Fonte: Autor.

Para a obtenção dos valores da energia de ativação para a massa específica $\left(E_{a}\right)$ foi empregado o método de linearização de curvas proposto por Freund (2004), na qual a Equação 2 é reescrita na forma de: 


$$
\ln \rho=\ln \rho_{\infty}+\left(\frac{E_{a}}{R}\right) \cdot \frac{1}{T}
$$

Tabela 5. Valores estimados para a massa específica dos ésteres estearato de metila e ariquidato de metila

\begin{tabular}{ccc}
\hline Temperatura (K) & $\begin{array}{c}\text { Estearato de } \\
\text { metila }\left(\mathrm{kg} \cdot \mathrm{m}^{-3}\right)\end{array}$ & $\begin{array}{c}\text { Ariquidato de } \\
\text { metila }\left(\mathrm{kg} \cdot \mathrm{m}^{-3}\right)\end{array}$ \\
\hline 293,15 & 863,8 & 862,7 \\
303,15 & 856,3 & 855,3 \\
313,15 & 848,9 & 847,9 \\
323,15 & 841,5 & 840,5 \\
333,15 & 834,1 & 833,1 \\
343,15 & 826,7 & 825,7 \\
353,15 & 819,3 & 818,3 \\
363,15 & 811,9 & 810,9 \\
373,15 & 804,5 & 803,4 \\
383,15 & 797,1 & 796,0 \\
\hline
\end{tabular}

Fonte: Autor.

O gráfico $\ln \rho$ versus $\frac{1}{T}$ fornece uma reta, em que o coeficiente angular corresponde à razão $\frac{E_{a}}{R}$ e o coeficiente linear, à $\ln \rho_{\infty}$.

Com base nos dados indicados nas Tabelas 2, 3, 4 e 5, os valores da razão $\frac{E_{a}}{R} \mathrm{e}$ $\ln \rho_{\infty}$ foram obtidos a partir da análise de regressão linear dos valores de $\ln \rho$ em função de $\frac{1}{T}$ para cada éster metílico, conforme indicados pelas Equações 5 e 6 .

$\frac{E_{a}}{R}=\frac{\left\{n \cdot\left[\sum_{i=1}^{n}\left(\frac{1}{T}\right) \cdot \ln \rho\right]-\left[\sum_{i=1}^{n}\left(\frac{1}{T}\right) \cdot \sum_{i=1}^{n} \ln \rho\right]\right\}}{\left\{n \cdot\left[\sum_{i=1}^{n}\left(\frac{1}{T}\right)^{2}\right]-\left[\sum_{i=1}^{n}\left(\frac{1}{T}\right)\right]^{2}\right\}}$

$$
\ln \rho_{\infty}=\frac{\left\{\left(\sum_{i=1}^{n} \ln \rho\right)-\left(\frac{E_{a}}{R}\right) \cdot\left(\sum_{i=1}^{n} \frac{1}{T}\right)\right\}}{n}
$$

As Equações 5 e 6 determinam, respectivamente, os valores de $\frac{E_{a}}{R}$ e $\ln \rho_{\infty}$, sendo adaptadas do trabalho de Triola (2008).

A Equação 7 determina o valor do coeficiente de correlação linear $\left(r^{2}\right)$ para a análise de regressão linear dos dados emparelhados de $\ln \rho$ e $\frac{1}{T}$.

A Equação 7 foi adaptada do trabalho de Triola (2008).

$$
r^{2}=\frac{\left\{n \cdot \sum_{i=1}^{n}\left\{\left(\frac{1}{T}\right) \cdot(\ln \rho)\right\}-\left\{\left[\sum_{i=1}^{n}\left(\frac{1}{T}\right)\right] \cdot\left[\sum_{i=1}^{n} \ln \rho\right]\right\}\right\}}{\left\{\left\{\left[n \cdot \sum_{i=1}^{n}\left(\frac{1}{T}\right)^{2}\right]-\left[\sum_{i=1}^{n}\left(\frac{1}{T}\right)\right]^{2}\right\}^{1 / 2} \cdot\left\{\left[n \cdot \sum_{i=1}^{n}(\ln \rho)^{2}\right]-\left[\sum_{i=1}^{n} \ln \rho\right]^{2}\right\}^{1 / 2}\right\}}
$$

Nas Equações 5, 6 e 7, $n$ corresponde ao número de dados emparelhados de $\ln \rho$ em função de $\frac{1}{T}$, que de acordo com as Tabelas 2, 3, 4 e 5, equivale a 10.

\section{RESULTADOS E DISCUSSÃO}

As Figuras 1, 2, 3 e 4 representam os gráficos de $\ln \rho$ versus $\frac{1}{T}$ para cada um dos ésteres metílicos de ácidos graxos estudados.

Pode-se observar nas Figuras 1, 2, 3 e 4, o comportamento linear entre $\ln \rho$ em função de $\frac{1}{T}$ e que à medida em que se 
aumenta a razão $\frac{1}{T}$ ocorre um aumento para $\ln \rho$.

Figura 1: Gráfico de $\ln \rho$ em função $\frac{1}{T}$ para os ésteres miristato de metila e linoleato de metila

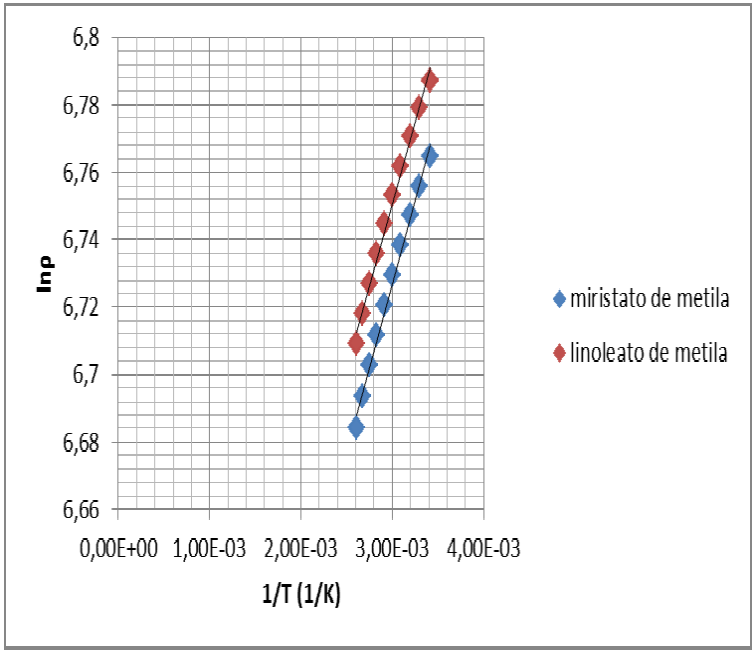

Fonte: Autor.

Figura 2: Gráfico de $\ln \rho$ em função $\frac{1}{T}$ para os ésteres pentadecanoato de metila e palmitoleato de metila

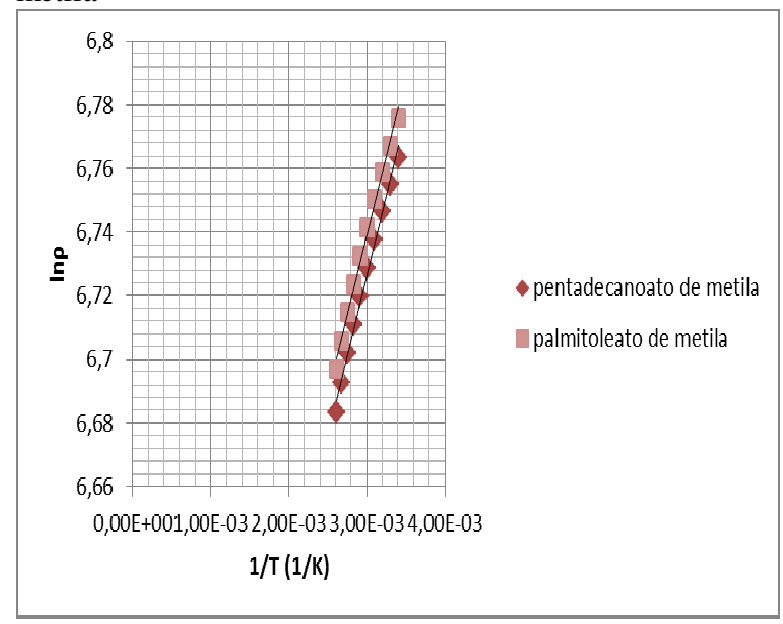

Fonte: Autor.

A Tabela 6 relaciona os resultados obtidos através das Equações 5, 6 e 7.
Figura 3: Gráfico de $\ln \rho$ em função $\frac{1}{T}$ para os ésteres palmitato de metila e oleato de metila

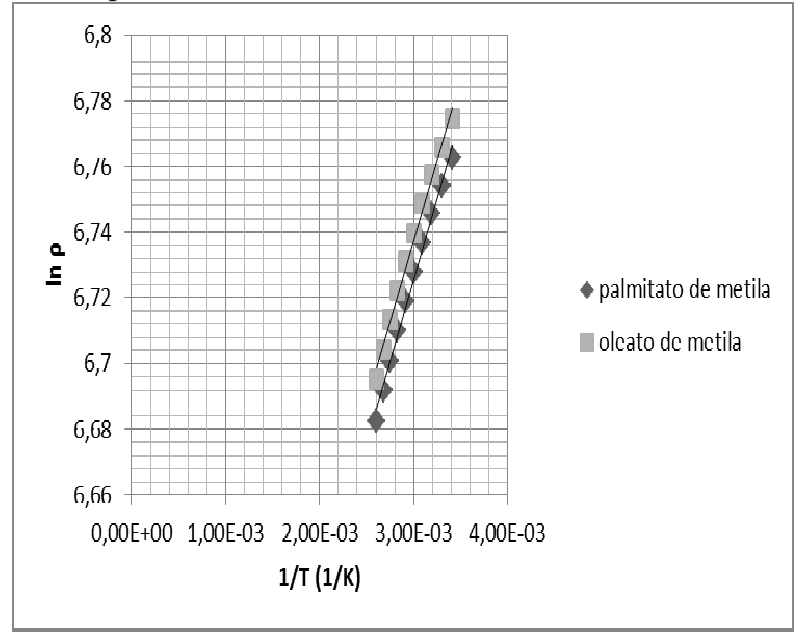

Fonte: Autor.

Figura 4: Gráfico de $\ln \rho$ em função $\frac{1}{T}$ para os ésteres estearato de metila e ariquidato de metila

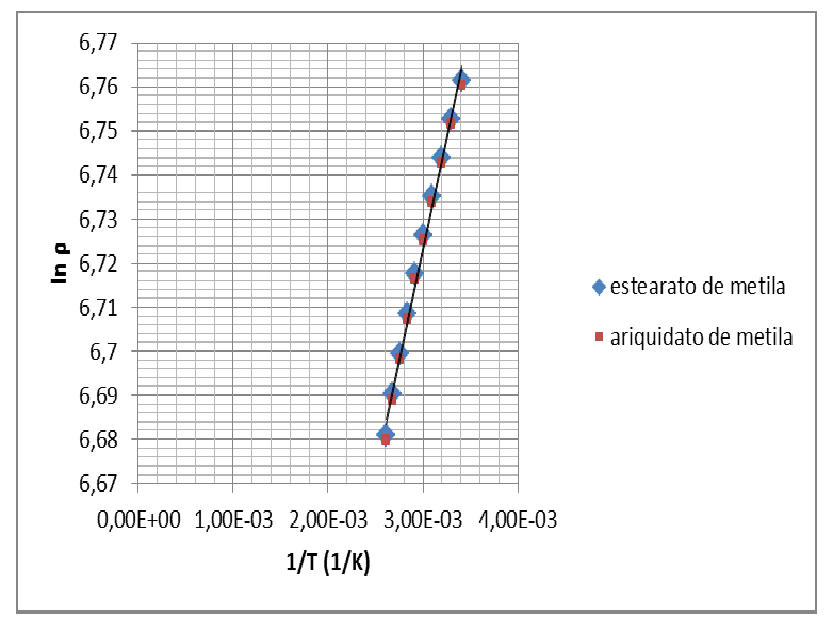

Fonte: Autor.

Tabela 6. Valores obtidos para $\frac{E_{a}}{R}, \ln \rho_{\infty}$ e $r^{2}$

\begin{tabular}{|c|c|c|c|}
\hline $\begin{array}{l}\text { Éster metílico de } \\
\text { ácido graxo }\end{array}$ & $\frac{E_{a}}{R}(\mathrm{~K})$ & $\ln \rho_{\infty}$ & $r^{2}$ \\
\hline Miristato de metila & 99,7525 & 6,4278 & 0,9962 \\
\hline $\begin{array}{l}\text { Pentadecanoato de } \\
\text { metila }\end{array}$ & 99,8459 & 6,4265 & 0,9961 \\
\hline Palmitato de metila & 99,9778 & 6,4253 & 0,9963 \\
\hline $\begin{array}{l}\text { Palmitoleato de } \\
\text { metila }\end{array}$ & 98,6043 & 6,4430 & 0,9963 \\
\hline Linoleato de metila & 97,3936 & 6,4586 & 0,9962 \\
\hline Oleato de metila & 98,6663 & 6,4413 & 0,9963 \\
\hline Estearato de metila & 99,9886 & 6,4237 & 0,9963 \\
\hline Ariquidato de metila & 100,2525 & 6,4217 & 0,9962 \\
\hline
\end{tabular}

Fonte: Autor. 
Pinheiros e coautores (2009) comentam que o coeficiente de correlação linear $\left(r^{2}\right)$ mede a interdependência linear entre as variáveis e avalia a qualidade do ajuste, ou seja, quanto mais próximo o coeficiente de correlação linear for da unidade, melhor o ajuste da reta em relação aos pontos da dispersão.

Pode-se observar na Tabela 6 que o coeficiente de correlação linear, para todos os ésteres metílicos de ácidos graxos estudados, está próximo da unidade.

Lira (2004) e Carvalho (2005) comentam que a correlação linear é classificada como muito forte quando os valores do coeficiente de correlação linear são maiores ou iguais a 0,90 e menores que 1,0 . Dessa forma, para todos os ésteres metílicos de ácidos graxos estudados, a correlação linear é classificada como muito forte.

A Tabela 7 indica os valores da energia de ativação para a massa específica $\left(E_{a}\right)$ e da massa específica quando a temperatura tende ao infinito $\left(\rho_{\infty}\right)$.

No cálculo para a determinação dos valores da energia de ativação para a massa específica, considerou-se que o valor da constante universal dos gases ideais $(R)$ equivale a $8,314 \quad \mathrm{~J} \cdot \mathrm{mol}^{-1} \cdot \mathrm{K}^{-1} \quad(\mathrm{NETZ}$ e ORTEGA, 2008).

Pode-se observar na Tabela 7 que o éster ariquidato de metila $\left(\mathrm{C}_{21} \mathrm{H}_{42} \mathrm{O}_{2}\right)$ apresentou o maior valor de energia de ativação para a massa específica e o menor valor para a massa específica quando a temperatura tende ao infinito, em comparação com os demais ésteres. Com relação ao éster linoleato de metila $\left(\mathrm{C}_{19} \mathrm{H}_{34} \mathrm{O}_{2}\right)$, este apresentou o menor valor de energia de ativação para a massa específica e o maior valor para a massa específica quando a temperatura tende ao infinito, em comparação com os demais ésteres.

Tabela 7. Valores obtidos para $E_{a}$ e $\rho_{\infty}$

\begin{tabular}{ccc}
\hline $\begin{array}{c}\text { Éster metílico de } \\
\text { ácido graxo }\end{array}$ & $E_{a}\left(\mathrm{~J} \mathrm{~mol}^{-1}\right)$ & $\rho_{\infty}\left(\mathrm{Kg} \cdot \mathrm{m}^{-3}\right)$ \\
\hline Miristato de metila & 812,75 & 618,81 \\
Pentadecanoato de & 830,16 & 618,01 \\
metila & & \\
Palmitato de metila & 831,26 & 617,27 \\
Palmitoleato de & 819,84 & 628,29 \\
metila & & \\
Linoleato de metila & 809,77 & 638,17 \\
Oleato de metila & 820,35 & 627,22 \\
Estearato de metila & 831,35 & 616,28 \\
Ariquidato de metila & 833,54 & 615,05 \\
\hline Fonte: Autor. & &
\end{tabular}

Veny e coautores (2009) relatam que a massa específica de ésteres metílicos de ácidos graxos depende da massa molar, do conteúdo de ácidos graxos livres, do conteúdo de água e da temperatura.

A Figura 5 ilustra o gráfico da energia de ativação para a massa específica em função da massa molar. Nesse gráfico, para efeito de comparação, foram considerados apenas os ésteres metílicos de ácidos graxos saturados, ou seja, os ésteres miristato de metila, pentadecanoato de metila, palmitato de metila, estearato de metila e araquidato de metila. 
Observa-se na Figura 5, que na medida em que se aumenta a massa molar do éster metílico de ácido graxo saturado, maior é a energia de ativação para a massa específica.

Figura 5: Gráfico da energia de ativação para a massa específica em função da massa molar de ésteres metílicos de ácidos graxos saturados

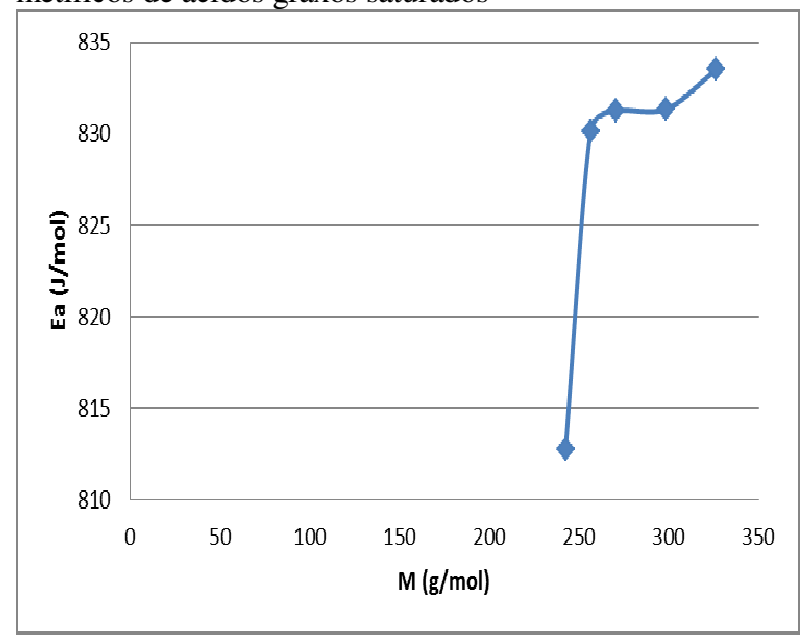

Fonte: Autor.

Lôbo e coautores (2009) comentam que algumas propriedades do biodiesel estão relacionadas com as estruturas moleculares dos seus alquil-ésteres constituintes. Dentre essas propriedades, destacam-se: massa específica, viscosidade cinemática, índice de iodo, fração de destilados, número de cetano, ponto de névoa, ponto de entupimento de filtro a frio e ponto de fluidez.

Segundo Santos (2008), os ácidos graxos diferem basicamente um do outro pelo comprimento da cadeia carbônica e a posição das duplas ligações (insaturações).

No caso dos ácidos graxos saturados (ácidos mirístico, pentadecanóico, palmítico, esteárico e araquídico), esSes se organizam com facilidade na forma de cristais, devido às forças intermoleculares do tipo van der Waals (SOLOMONS E FRYHLE, 2009).

No caso dos ácidos graxos insaturados (ácidos palmitoleico, linoleico e oleico), as ligações duplas estão localizadas na cadeia, de forma não conjugada (sistema 1,4-diênico), frequentemente, separadas por grupos metilênicos $\left(-\mathrm{CH}_{2}-\right)$. Assim, as duas unidades da molécula encontram-se num dos lados da ligação dupla, assumindo a configuração espacial do tipo cis (Z). A configuração cis de um ácido graxo insaturado impõe uma curva rígida à cadeia carbônica, que interfere na organização cristalina, causando uma redução nas forças intermoleculares do tipo van der Waals (SANTOS, 2008; SOLOMONS e FRYHLE, 2009).

Dessa forma, os resultados sugerem que, no caso dos ésteres metílicos de ácidos graxos saturados, na medida em que se aumenta a cadeia carbônica, aumenta-se a energia de ativação para a massa específica, pois esses ésteres apresentam forças intermoleculares do tipo van der Waals mais intensas.

No caso dos ésteres metílicos de ácidos graxos insaturados, os resultados sugerem que, na medida em que o número de ligações duplas (insaturações) aumenta, diminui a energia de ativação para a massa específica, pois a configuração cis impõe uma curva rígida à cadeia carbônica, reduzindo a atuação das forças intermoleculares do tipo van der Waals. 
O fato do éster oleato de metila $\left(\mathrm{C}_{19} \mathrm{H}_{36} \mathrm{O}_{2}\right)$ apresentar uma maior energia de ativação para a massa específica em relação ao éster palmitoleato de metila $\left(\mathrm{C}_{17} \mathrm{H}_{32} \mathrm{O}_{2}\right)$ pode estar associado a um tamanho da cadeia carbônica maior do oleato em relação ao palmitoleato, pois ambos possuem apenas uma insaturação (ligação dupla).

Considerando que a energia de ativação para a massa específica indica a sensibilidade da massa específica devido à variação da temperatura, os resultados sugerem que o éster ariquidato de metila $\left(\mathrm{C}_{21} \mathrm{H}_{42} \mathrm{O}_{2}\right)$ apresenta uma maior sensibilidade da massa específica em virtude da variação da temperatura, em comparação aos demais ésteres metílicos de ácidos graxos saturados estudados.

Com o mesmo raciocínio, o éster oleato de metila $\left(\mathrm{C}_{19} \mathrm{H}_{36} \mathrm{O}_{2}\right)$ apresenta uma maior sensibilidade da massa específica em virtude da variação da temperatura, em comparação aos demais ésteres metílicos de ácidos graxos insaturados estudados.

Recomenda-se que o comportamento da massa específica de ésteres metílicos de ácidos graxos em relação à temperatura, ao tamanho da cadeia carbônica e ao número de insaturações seja estudado mais profundamente.

Buscando na literatura trabalhos associados à energia de ativação para a massa específica de ésteres metílicos de ácidos graxos, constatou-se a ausência desse estudo, o que dificultou as análises dos resultados obtidos nesse trabalho.

\section{CONCLUSÃO}

O objetivo desse trabalho foi avaliar o efeito da temperatura sobre a massa específica dos ésteres metílicos de ácidos graxos miristato de metila, pentadecanoato de metila, palmitato de metila, palmitoleato de metila, estearato de metila, oleato de metila, linoleato de metila e ariquidato de metila.

A ausência na literatura de valores experimentais da energia de ativação para a massa específica $\left(E_{a}\right)$ e da massa específica quando a temperatura tende ao infinito $\left(\rho_{\infty}\right)$ dos ésteres metílicos estudados dificultou a comparação com os valores encontrados nesse trabalho.

Os resultados sugerem que, no caso dos ésteres metílicos de ácidos graxos saturados, na medida em que se aumenta a cadeia carbônica, aumenta-se a energia de ativação para a massa específica, em virtude das forças intermoleculares do tipo van der Waals serem mais intensas.

No caso dos ésteres metílicos de ácidos graxos insaturados, os resultados sugerem que, na medida em que o número de ligações duplas (insaturações) aumenta, diminui a energia de ativação para a massa específica, em virtude da redução das forças intermoleculares do tipo van der Waals. 
O éster ariquidato de metila apresentou o maior valor de energia de ativação para a massa específica e o menor valor para a massa específica quando a temperatura tende ao infinito, em comparação aos demais ésteres.

Os valores encontrados da energia de ativação para a massa específica variaram de $809,77{\mathrm{~J} . \mathrm{mol}^{-1}}^{-1}$ (linoleato de metila) a 833,54 J.mol ${ }^{-1}$ (ariquidato de metila).

$\mathrm{O}$ éster ariquidato de metila apresentou uma maior sensibilidade da massa específica em virtude da variação da temperatura, em comparação aos demais ésteres metílicos de ácidos graxos saturados estudados.

Já o éster oleato de metila apresentou uma maior sensibilidade da massa específica em virtude da variação da temperatura, em comparação aos demais ésteres metílicos de ácidos graxos insaturados estudados.

\section{REFERENCIAS}

CARVALHO, M. J. S. Quimiometria e espectroscopia no infravermelho próximo (NIR) e médio (MIR) aplicadas na análise de óleos lubrificantes. Dissertação de Mestrado em Química do Instituto Militar de Engenharia, 2005. 121p.

CAVALCANTE, R. M. Predição da densidade de biodiesel proveniente de diferentes matérias-primas. Dissertação de Mestrado em Tecnologia de Processos Químicos e Bioquímicos da Universidade Federal do Rio de Janeiro, 2010. 80p.

ENCARNAÇÃO, A. P. G. Geração de biodiesel pelos processos de transesterificação e hidroesterificação: uma avaliação econômica. Dissertação de Mestrado em Tecnologia de Processos Químicos e Bioquímicos da Universidade Federal do Rio de Janeiro, 2007. 144p.

FREUND, J. E. Estatística aplicada Economia, Administração e Contabilidade.

Artmed, Porto Alegre, 2004. 545p.

GARCIA, C. M. Transesterificação de óleos vegetais. Dissertação de mestrado em Química da Universidade Estadual de Campinas, 2006. 136p.

GIAP, S. G. E. The hidden property of Arrhenius-type relationship: viscosity as a function of temperature. Journal of Physical Science, v. 2, n. 1, p. 29-39, 2010.

LIRA, S. A. Análise de correlação:

abordagem teórica e de construção dos coeficientes com aplicação. Dissertação de

Mestrado em Ciências da Universidade Federal do Paraná, 2004. 196p.

LÔBO, I. P.; FERREIRA, S. L. C.; CRUZ, R. S. Biodiesel: parâmetros de qualidade e métodos analíticos. Química Nova, v. 32, n. 6, p. 1596-1608, 2009.

NETZ, P. A.; ORTEGA, G. G. Fundamentos de físico-química: uma abordagem conceitual para as ciências farmacêuticas. Artmed, Porto Alegre, 2008. 299p.

NICOLAU, A.; MARTINI, D. S.; REIZNAUTT, Q. B.; PEDROTTI, F.; DALCIN, F. M.; FRANKENBERG, J. C.; SAMIOS, D. Obtenção e caracterização de ésteres e poliésteres a partir de ácidos graxos insaturados. In: REUNIÃO ANUAL DA SOCIEDADE BRASILEIRA DE QUÍMICA, 30ª Águas de Lindóia. Anais. SBQ, 2007.

PEREIRA, E. A.; QUEIROZ, A. J. M.; FIGUEIRÊDO, R. M. F. Comportamento reológico de mel da abelha uruçu (Melipona scutellaris, L.). Ciências Exatas e Naturais, v. 5, n. 2, p. 179-186, 2003. 
PINHEIRO, J. I. D.; CUNHA, S. B.; CARVAJAL, S. R.; GOMES, G. C.

Estatística básica: a arte de trabalhar com dados. Elsevier, Rio de Janeiro, 2009. 295p.

SANTOS, N. A. Propriedades termo oxidativas e de fluxo do biodiesel de babaçu (Orbignya phalerata). Dissertação de Mestrado em Química da Universidade Federal da Paraíba, 2008. 129p.

SILVA, S. A. Estudo do comportamento reológico dos adesivos hot melt PSA e a sua relação com a composição e as propriedades adesivas. Dissertação de Mestrado em Engenharia Química da Universidade Federal do Rio Grande do Sul, 2008. 123p.

Dissertação (Mestrado) - Programa de Pósgraduação em Engenharia Química, Universidade Federal do Rio Grande do Sul, Porto Alegre.

SOLOMONS, T. W. G.; FRYHLE, C. B. Química Orgânica - Volume 2. LTC, Rio de Janeiro, 2009. 518p.

TSEN, J. H.; KING, V. A. E. Density of banana puree as a function of soluble solids concentration and temperature. Journal of Food Engineering, v. 55, p. 305-308, 2002.

TRIOLA, M. F. Introdução à Estatística. LTC, Rio de Janeiro, 2008. 720p.

VENY, H.; BAROUTIAN, S.; AROUA, M. K.; HASAN, M.; RAMAN, A. A.; SULAIMAN, N. M. N. Density of Jatropha curcas seed oil and its methyl esters: measurement and estimations. International Journal of Thermophysics, v. 30, p. 529-541, 2009.

VERDUZCO, L. F. R. Density and viscosity of biodiesel as a function of temperature: Empirical models. Renewable and Sustainable Energy Reviews, v. 19, p. 652-665, 2013. 